\title{
Where Is the "Meta" in Animal Metacognition?
}

\author{
Nate Kornell \\ Williams College
}

\begin{abstract}
Apes, dolphins, and some monkeys seem to have metacognitive abilities: They can accurately evaluate the likelihood that their response in cognitive task was (or will be) correct. These certainty judgments are seen as significant because they imply that animals can evaluate internal cognitive states, which may entail meaningful self-reflection. But little research has investigated what is being reflected upon: Researchers have assumed that when animals make metacognitive judgments they evaluate internal memory strength. Yet decades of research have demonstrated that humans cannot directly evaluate internal memory strength. Instead, they make certainty judgments by drawing inferences from cues they can evaluate, such as familiarity and ease of processing. It seems likely that animals do the same, but this hypothesis has not been tested. I suggest two strategies for investigating the internal cues that underlie animal metacognitive judgments. It is possible that animals, like humans, are capable of making certainty judgments based on internal cues without awareness or meaningful self-reflection.
\end{abstract}

Keywords: metacognition, humans, animals, certainty, confidence

In 1982, the United States Department of Agriculture (USDA) proposed a directive that would have reclassified ketchup as a vegetable. The goal was to allow cafeterias across the country to save money by eliminating a serving of vegetables from their school lunches. This proposal, which sparked outrage, was never implemented (Nestle, 2011). In the United States today, however, a piece of pizza counts as a serving of vegetable if it contains two tablespoons of tomato paste (Baertlein \& Abbott, 2011). Pizza is faintly vegetable-like, but it lacks essential vegetable properties that make schoolchildren healthy.

Researchers who study animal metacognition may be repeating the USDA's mistake. The essential property of metacognition is that monitoring one's own cognition involves self-reflection (Metcalfe \& Kober, 2005). Do the tasks that animals are asked to perform, in animal metacognition research, tap into this essential property? Or do these tasks, like tomato paste, lack essential properties? Answering this question requires examining the cues that guide metacognitive judgments, but a brief tour of the tasks used in animal metacognition research is necessary first.

\section{A Brief Overview of Animal Metacognition Tasks}

A growing literature suggests that some monkeys, apes, dolphins, and possibly other nonhuman animals ${ }^{1}$ can make metacognitive judgments about their perceptions and memories (for reviews, see Kornell, 2009; Smith, 2009; Smith, Beran, Couchman, Coutinho, \& Boomer, 2009; Terrace \& Son, 2009). In the first demonstration of this ability, Smith, Schull, Strote, McGee, Egnor,

This article was published Online First July 22, 2013.

Nate Kornell, Department of Psychology, Williams College.

Jessica Cantlon provided valuable feedback on a draft of this article.

Correspondence concerning this article should be addressed to Nate Kornell, Department of Psychology, Williams College, Williamstown, MA 01267. E-mail: nkornell@gmail.com and Erb (1995) played tones that ranged from 1,200-2,100 $\mathrm{Hz}$ for a dolphin (Tursiops truncatus). The dolphin's task was to select one response for $2,100 \mathrm{~Hz}$ tones and another response for any other tones. There was also a third response option that advanced the animal to an easier trial. The dolphin selected this third "uncertain" response primarily on the most difficult trials (i.e., those nearest $2,100 \mathrm{~Hz}$ ), suggesting that it could make certainty judgments. Rhesus monkeys (Macaca mulatta) performed similarly in a visual discrimination task (Shields, Smith, \& Washburn, 1997).

Other animal metacognition studies followed. In a seminal study of memory monitoring, Hampton (2001) showed Rhesus monkeys a sample picture and then asked them to select it from among three other pictures. On some trials, after the sample disappeared but before the test began, the monkeys had a choice: If they choose to skip the test they received a small reward, but if they chose to take the test they received either a larger reward or a timeout depending on whether they answered correctly or not. Memory test accuracy was lower when the test was required than when the animals had the option to decline the test but chose to take it, presumably because they selectively declined tests when they predicted they were likely to answer incorrectly.

In another study, Kornell, Son, and Terrace (2007) presented Rhesus monkeys with a confidence-like gambling task. Subjects made a response in a memory task and then they made a "bet" that was either low-risk (a small payoff regardless of memory-task accuracy) or high-risk (a large payoff after a correct answer but an equally large punishment after an error). High-risk responses occurred most often after correct responses. Moreover, because of training on prior tasks, accurate metacognitive responding began on the first day of the memory task, which suggests that instead of learning a task-specific response pattern, the animals had learned

\footnotetext{
${ }^{1}$ The term animals will be used to refer to non-human animals. In most cases, it refers to primates and dolphins that have demonstrated metacognitive abilities. Other animals, such as pigeons, have failed in metacognitive tasks (Sutton \& Shettleworth, 2008).
} 
to make confidence-like responses in a flexible, general way (also see Templer \& Hampton, 2012). Based on these findings and others, researchers have concluded that animals can make accurate certainty judgments.

\section{The Essential Feature of Metacognition}

It goes without saying that animals respond to environmental cues. They also respond to internal cues; for example, animals can learn to respond based on hunger and thirst (Bolles \& Petrinovich, 1954). Metacognition is different because it requires responding based on internal cognitive states. The ability to make certainty judgments suggests that animals can engage in self-reflection: they can look inward and evaluate the strength of their own memories. ${ }^{2}$ This apparent self-reflection seems to elevate metacognition above garden-variety judgments and cognitions in animals (e.g., Smith, 2009; Smith, Shields, \& Washburn, 2003; Terrace \& Metcalfe, 2005). Thus, articles about animal metacognition often claim that metacognitive behaviors require high-level cognitive abilities that correspond to self-reflection, awareness, or consciousness. They assert that metacognition has long been seen as uniquely human and use terms like, "The missing link in cognition," or the "Origins of self-reflective consciousness" (Terrace \& Metcalfe, 2005). It is crucial, though, to understand the nature of the cues animals rely on when they make certainty judgments. If the cues are not internal cognitive states, metacognition would lose its "metaness."

An ongoing debate about the cues that control metacognitive judgments centers on the possibility that allegedly metacognitive behavior can be accounted for by simple reinforcement models that explain behavior based on responses to external stimuli (e.g., Le Pelley, 2012). Many studies have aimed to demonstrate that simple reinforcement alone cannot explain metacognitive judgments. ${ }^{3}$ These studies have, in general, attempted to eliminate the possibility that external cues are solely responsible for controlling behavior (e.g., Beran, Smith, Coutinho, Couchman, \& Boomer, 2009; Couchman, Coutinho, Beran, \& Smith, 2010; Hampton, 2001; Kornell et al., 2007; Smith et al., 2008; Smith, Beran, Redford, \& Washburn, 2006).

Researchers have assumed that if they can exclude external cues, then animals must make metacognitive judgments by evaluating the strength of their memories. The reasoning seems safe: If animals act certain when they have strong memories, then they must be certain because they have strong memories. Unfortunately, this reasoning has been tested, and discredited, over the last four-plus decades of research on human metacognition. Humans cannot directly evaluate the strength of their memories, as I review in the next section.

Thus, an important question has been overlooked in the debate about the role of internal versus external cues: What internal cues guide judgments (see Hampton, 2001)? For example, if it turned out that animals make certainty judgments on the basis of their own response time, would metacognition retain the essential features that make it interesting? Examining questions about external cues (and simple reinforcement) but assuming internal cues do not need to be scrutinized is like checking a car's tires but assuming the engine is fine-even though the human engine held surprises.

\section{Direct Access Versus Inference}

Early research on human metacognition (e.g., Hart, 1967; for a brief history, see Son \& Kornell, 2008) endorsed what came to be known as the direct access view (Schwartz, Benjamin, \& Bjork, 1997). The reasoning was straightforward: Memory judgments are made based on an internal analysis of the memories being judged, and high levels of certainty are caused by the presence of strong memories.

The direct access view predicts that memory judgments should be correlated with memory strength. However, evidence has been accumulating for the last four decades that is at odds with this prediction (e.g., Schwartz et al., 1997). For example, presenting words in small versus large type size affects metacognitive judgments but does not affect memory (Kornell, Rhodes, Castel, \& Tauber, 2011; Rhodes \& Castel, 2008). Words presented loudly are also rated as more memorable than words presented quietly, again incorrectly (Rhodes \& Castel, 2009). Size and volume affect the ease (or fluency) with which people process information. Other factors, such as familiarity or recency, also increase ease of processing. Ease of processing has a strong influence on metacognitive judgments, even, as many studies have shown, when it does not affect memory (e.g., Alter \& Oppenheimer, 2009; Begg, Duft, Lalonde, Melnick, \& Sanvito, 1989; Kelley \& Jacoby, 1996; Matvey, Dunlosky, \& Guttentag, 2001; Undorf \& Erdfelder, 2011). In short, human certainty judgments vary systematically when memory strength does not.

Other studies have gone further, creating situations where memory and certainty are negatively correlated. For example, in a study by Benjamin, Bjork, and Schwartz (1998), participants answered a list of trivia questions. After each question, they estimated the likelihood that they would remember their answer on a subsequent free-recall test (that is, the questions were not presented on the test, which was made clear to the participants). When participants thought of an answer quickly during the first phase, they were more likely to give it a high metacognitive judgment (i.e., predict that they were likely to remember it on the free recall test), but they were less likely to remember it when the time came to take the test. Because participants relied on ease of processing (the items they recalled quickly were easier to process), their judgments were diametrically opposed to actually memory strength. These findings demonstrate that when two cues-memory strength and ease of processing - send conflicting signals, metacognitive judgments correspond to ease of processing, not memory strength (also see, e.g., Begg et al., 1989; Besken \& Mulligan, 2013).

Based on findings like these, researchers who study human metacognition have largely rejected the direct access view. It has been replaced by the inferential view, which holds that people

\footnotetext{
${ }^{2}$ There are two basic kinds of metacognitive task: memory tasks and perceptual discrimination tasks. In this article I focus on memory tasks because perceptual tasks are subject to the objection that they can be responded to based on external stimuli that are present at the time of the response. Thus, the gold standard for demonstrating metacognition in animals has been the ability to evaluate the strength of one's own memories (e.g., Smith, 2009; Kornell, 2009).

${ }^{3}$ There is nothing problematic about reward per se. If an animal responds based on metacognitive cues, then its behavior should be considered metacognitive. The question is whether behavior can be explained without reference to internal metacognitive cues.
} 
cannot assess the strength of their memories directly. Instead, people rely on cues we can directly experience, such as the ease with which an answer comes to mind (e.g., Benjamin \& Bjork, 1996; Koriat, 1997; Reder \& Ritter, 1992). Animal metacognition researchers continue to endorse the direct access view when they (1) assume that humans can monitor the strength of their memories and (2) claim they have evidence that animals can do so as well.

\section{Animal Paradigms and Their Analogues}

In most research supporting the inferential view, including the research reviewed above, participants have made judgments of learning: They have judged the probability that they will be able to recall an answer later (e.g., Benjamin et al., 1998; Besken \& Mulligan, 2013; Kornell et al., 2011; Rhodes \& Castel, 2008, 2009). Animals are not generally asked to make predictions about how they will do on a test that will take place later. They typically judge the accuracy of their memory right now. Thus, many of the studies that support the direct access view in humans do not have analogs in the literature on animal metacognition. However, for each of the three animal paradigms that I reviewed at the outset of this article, there is at least one analogous study that has been conducted with humans, as I review next.

The escape response paradigm, in which subjects can decide whether or not they want to answer on a given trial, is the most widespread measure of animal metacognition (e.g., Smith, 2009). It has a parallel in a paradigm used by Reder and Ritter (1992), who also asked participants whether they wanted to make a response. Participants were asked to multiply two 2-digit numbers (e.g., $22 \times 47)$. The same numbers appeared frequently, sometimes together and sometimes separately (e.g., 22 without 47). Before answering each question, participants were asked to quickly decide whether they could retrieve the answer from memory or would have to compute it. These judgments were mainly influenced by the participants' familiarity with the numbers in the question (e.g., 22 and 47), not by their knowledge of the answer (i.e., 1034). Similarly, Reder (1987) used a "game show" paradigm in which participants had to decide quickly whether or not to "ring in"- that is, whether or not they knew the answer-without waiting to think of the answer first. Participants were more confident that they could answer questions (e.g., what is the term in golf for one under par?) in which some of the words had been primed (e.g., golf, par), even when the primes did not actually increase response accuracy. In these paradigms, like in the escape response paradigm (which has been used with a memory task; Smith, Shields, Allendoerfer, \& Washburn, 1998), the judgment being made was whether or not the participant wanted to answer. The evidence suggests that humans' metacognitive responses were made based on ease of processing, not memory strength, in these paradigms.

Hampton (2001) introduced another paradigm reviewed earlier, in which animals could chose to avoid taking a recognition test, that has provided convincing evidence of animal metacognition. It has a parallel in research by Schwartz and Metcalfe (1992). In the first phase of their procedure, participants made pleasantness ratings that primed certain words that would appear later in the experiment. Next, participants learned word pairs (e.g., moonnoon) and then took a test. During the test, when they could not think of the answer, they were asked to rate the probability that they would be able to select the answer on a recognition test.
During the first phase, the researchers had independently primed either the cue (e.g., moon) or the target response (e.g., noon). They found that feeling of knowing varied as a function of cue fluency but the fluency of the target response did not affect judgments. Like in Hampton's (2001) paradigm, participants had to judge their ability to recognize an answer on a test that would occur almost immediately. Again, the human results suggested that ease of processing of the cue, not target memory strength, guided metacognitive judgments (also see Metcalfe, Schwartz, \& Joaquim, 1993).

Kornell et al. (2007) introduced a third influential paradigm by asking monkeys to make "bets" after they had made a response in a memory task. This paradigm has a parallel in research by Kelley and Lindsay (1993). Before human participants were asked a set of general knowledge questions (e.g., "What was Buffalo Bill's last name?), they were shown one of three types of prime: the correct answer (e.g., Cody), an unrelated answer (e.g., Melville), or an incorrect but related answer (e.g., Hickock). Being primed with an incorrect answer made participants give that answer more often and faster than when they were primed with an unrelated answer. Most important, priming increased participants' confidence in the incorrect answer they had just given. (Being primed with the correct answer had a similar effect.) Like in Kornell et al.'s (2007) paradigm, participants were asked to make a retrospective judgment about the accuracy of a response they had just made. The human results supported the view that ease of processing controlled metacognitive judgments.

To summarize, three important animal metacognition paradigms have analogues in human metacognition paradigms, and humans appear to make judgments based on ease of processing, not memory strength, in all cases. Although the paradigms used with humans and animals are not identical, one thing seems clear, given the evidence: It would be unwise to assume that animals are making judgments based on direct access to memory strength. Perhaps the assumption should be that animal judgments are inferential until evidence is gathered that proves otherwise.

In defense of the direct access view, it is possible that people rely on direct access to make simple metacognitive judgments and only resort to making inferences in metacognitively demanding situations. For example, there is probably some truth to the idea that humans know when they have a memory and when they do not. Most people can rightly report that they have absolutely no idea what the plastic or metal end of a shoelace is called (aglet) but do remember what the rounded utensil used to dig food is called (spoon). Even in these cases, though, people may make judgments based on inferences (e.g., Jameson, Narens, Goldfarb, \& Nelson, 1990). Moreover, in animal metacognition paradigms, the typical judgment is not about whether the animal has a memory or not. The animal has either just seen, or is looking at, the stimulus it is supposed to judge, so drawing a complete blank seems unlikely. In short, if humans and other animals are similar, it may be in their reliance on inferential cues, but this is an empirical question.

\section{Do Animals Base Their Judgments on Sufficiently Metacognitive Cues?}

To a human metacognition researcher, retrieval fluency is a perfectly valid metacognitive cue. For example, a study mentioned earlier found that recalling an answer quickly was associated with 
giving relatively high metacognitive ratings (Benjamin et al., 1998). To animal metacognition researchers, on the other hand, a metacognitive judgment made based on reaction time (RT) is not sufficiently metacognitive. The implicit assumption is that animals' certainty judgments are more sophisticated than that (in particular, they are made based on direct access to memory strength). It is likely that this assumption is misguided, given that (a) it suggests that animals take a more sophisticated approach to certainty judgments than humans do, and (b) there is no evidence to support it. (Ironically, my colleagues and I adopted this assumption when we tried to demonstrate that our monkeys' metacognitive responses could not be explained based on RT alone; Kornell et al., 2007.).

The question, then, is do the specific tasks used with animals require self-reflection? The direct access view might answer yes: the animals examine their own memories. From the inferential view, though, this question raises another: What cues do animals rely on to make their judgments? Do animals, like humans, rely on cues like ease of processing? As I discuss next, it may be possible to answer this question empirically.

\section{The Importance of Metacognitive Errors}

One way to understand the processes underlying metacognitive judgments is to examine metacognitive errors. Metacognitive errors occur when memory performance does not match memory judgments. Research on such errors has been crucial in human metacognition research. When cues like ease of processing and RT lead to accurate judgments (see, e.g., Dunlosky \& Nelson, 1992; Jacoby \& Kelley, 1987; Nelson, Dunlosky, Graf, \& Narens, 1994), it is difficult to disentangle the effect of memory strength from the effects of other cues. Metacognitive errors help isolate memory strength and identify the cues that control metacognitive judgments. Thus, the human metacognition literature is a parade of research on systematic heuristics, errors, and biases (see Bjork, Dunlosky, \& Kornell, 2012; Dunlosky \& Bjork, 2008).

There is no evidence that animals are prone to systematic metacognitive errors or biases, not necessarily because the biases do not exist, but because thus far, research paradigms have supported accurate responding. Ironically, examining errors might be the best way to demonstrate animals' metacognitive accomplishments. According to explanations based on simple reinforcement (cf. Le Pelley, 2012), animals' ostensibly metacognitive responses are actually learned behaviors that maximize reward. If a study were conducted in which systematic metacognitive errors caused animals to escape or decline test trials when they were likely to be correct, or to make high-risk bets when they were likely to be incorrect, their metacognitive responding would diminish reward. Systematic metacognitive errors that either did not affect, or deceased, reward rates would be difficult to explain based on simple reinforcement.

Next I propose two specific paradigms that could be used to investigate metacognitive errors. These paradigms put two cues, such as ease of processing and memory strength, in opposition. If each cue pushes judgments in a different direction, examining where the judgments end up can indicate which cue influences behavior more.

In the first paradigm, animals would be trained to respond based on abstract properties of a stimulus rather than its surface features.
In such a tasks, it is theoretically possible to manipulate perceptual fluency without manipulating task performance. For example, assume a monkey has learned to make metacognitive judgments about a primary task in which he is meant to select squares but not other rectangles. He could then be presented with the same task, but the ease of processing of the shapes could be manipulated by presenting them in high or low contrast. Low contrast leads humans to be less certain in a variety of tasks, even when it does not impair their task performance (e.g., Alter \& Oppenheimer, 2008, 2009). The same might be true of animals. Perceptual fluency could be manipulated without affecting task accuracy in many abstract tasks, such as when animals make numerical judgments, judgments of relative size, and so on.

A second specific proposal would require animals to learn to associate cues with targets, as often happens in research on human metacognition. If animals are like humans, manipulating the fluency of the cue might impact metacognitive judgments even when it does not affect their memory of the cue-target association (see Schwartz \& Metcalfe, 1992). For example, assume a monkey had learned to associate two pictures, so that when she was shown a cue picture, she could pick out the associated target from among distractors. If this monkey were shown the cue alone and asked to make a metacognitive judgment, the familiarity of the cue might affect her judgment: She might be more certain about cues that had been preexposed earlier in the same session, as compared with cues that had not been preexposed. Presumably preexposing her to the cue would not affect her ability to select the target based on that cue.

If these proposed studies produced evidence that metacognitive judgments are affected by cues that do not affect task performance, it would suggest that, like humans, animals make metacognitive judgments based on cues like ease of processing, not memory strength itself. (It would be even more interesting to find convincing evidence to the contrary.) Such research could be valuable in multiple ways. First, it could demonstrate a parallel between humans and animals. Second, it could advance debate about whether simple reinforcement-which might struggle to explain metacognitive errors that do not increase reward rates-can explain ostensibly metacognitive behavior. Third, specific information about how animals make metacognitive judgments would provide grounding for a more informed debate about whether animals (and humans, for that matter) engage in meaningful selfreflection when they make certainty judgments. I address this third point next.

\section{The Varieties of Metacognitive Experience}

In all paradigms used to date, ${ }^{4}$ animals' metacognitive choices have boiled down to two options: certain or uncertain (see Kornell, 2009). Are the essential properties of metacognition-self-reflection on internal cognitive states-present in these certainty judgments? In humans, certainty judgments do not appear to require conscious processing (Reder \& Schunn, 1996; Son \& Kornell, 2005). Indeed, feelings of certainty, or lack thereof, are so common that they usually

\footnotetext{
${ }^{4}$ Animal metacognition paradigms come in many varieties (e.g., Beran, Smith, \& Perdue, 2013; Call, 2010; Call \& Carpenter, 2001; Couchman et al., 2010; Crystal \& Foote, 2011; Inman \& Shettleworth, 1999; Redford, 2010).
} 
occur without being noticed (Kornell, 2009). For example, every time you go somewhere without checking a map or asking for directions you make an implicit assessment that you know how to get there. But you are not always conscious of this assessment. Animal navigation surely involves similar implicit judgments. Similarly, animals will seek more information when they do not know where food is hidden, but reach directly for the food when they do (Call, 2010; Call \& Carpenter, 2001; Hampton, Zivin, \& Murray, 2004; Hampton, 2009).

In addition, even if some certainty judgments are made consciously, it is not clear that animal metacognition tasks would involve self-reflection. In a self-reflective judgment, the subject of the judgment is the self (e.g., in a successful mark test, an animal recognizes itself in a mirror; Gallup, 1970). In animal metacognition research, the subject of the judgment is a perception or memory of an external stimulus (Metcalfe, 2003). In other words, saying "that picture is familiar" is a judgment about the familiarity of the picture, not a judgment about oneself.

Part of the reason why researchers have linked self-reflection and animal metacognition may be faulty syllogistic reasoning. If we posit two premises - that human metacognitive judgments can involve self-reflection and that animals make metacognitive judgments-we can conclude that animals must engage in selfreflection too. The problem is, there are many varieties of human metacognition. Some clearly involve self-monitoring: Humans think constantly about specific cognitions (e.g., "what was I thinking?") and our cognitive systems more generally (e.g., "I am bad at remembering names"; see Magnussen, Andersson, Cornoldi, De Beni, Endestad, Goodman, et al., 2006). We also have metacognitive experiences that can be all-too-conscious, such as the tip of the tongue experience (Schwartz, 2002). These examples, though, bear only a passing resemblance to certainty judgments. Humans and animals seem to perform similarly in simple metacognitive tasks (e.g., Smith et al., 2003), but there is scant evidence that animals engage in the varieties of metacognition that require self-reflection. There are metacognitive fields where only humans seem to play.

It might seem that even without self-reflection, being able to monitor certainty is an impressive cognitive feat for an animal. Do animals monitor certainty? Probably not, because certainty is an effect, not a cause. Consider what happens when an animal sees a picture in an experiment: Familiarity with the picture, and the associated ease of processing, causes it to arrive at a metacognitive judgment and make a response. In the same situation, a person might have an additional feeling of certainty, but whether an animal feels uncertain is difficult to tell. Thus, certainty judgment is a useful term, but it is hard to know whether certainty is relevant in animals: certainty judgments are not made based on certainty, and they do not necessarily lead to feelings of certainty either.

\section{Conclusion}

Metacognition is often viewed as a special ability that requires sophisticated higher-order cognition (e.g., Terrace \& Metcalfe, 2005). It may be time to question this view (cf. Hampton, 2009). Animals probably make certainty judgments in the same way humans do: by drawing inferences based on cues like ease of processing and RT, not by directly accessing the strength of their memories. How animals make certainty judgments is an empirical question. Animal tasks tend to resemble the sort of metacognitive tasks that require neither self-reflection nor consciousness in humans. They are metacognitive but not exactly self-reflective, just like tomato paste is nourishing but not exactly a vegetable.

\section{References}

Alter, A. L., \& Oppenheimer, D. M. (2009). Uniting the tribes of fluency to form a metacognitive nation. Personality and Social Psychology Review, 13, 219-235. doi:10.1177/1088868309341564

Baertlein, L., \& Abbott, C. (2011). House protects pizza as a vegetable. Reuters. Retrieved October 26, 2012, from http://www.reuters.com/ article/2011/11/18/us-usa-lunch-idUSTRE7AH00020111118.

Begg, I., Duft, S., Lalonde, P., Melnick, R., \& Sanvito, J. (1989). Memory predictions are based on ease of processing. Journal of Memory and Language, 28, 610-632. doi:10.1016/0749-596X(89)90016-8

Benjamin, A. S., \& Bjork, R. A. (1996). Retrieval fluency as a metacognitive index. In L. M. Reder (Ed.), Implicit memory and metacognition (pp. 309-338). Mahwah, NJ: Erlbaum.

Benjamin, A. S., Bjork, R. A., \& Schwartz, B. L. (1998). The mismeasure of memory: When retrieval fluency is misleading as a metamnemonic index. Journal of Experimental Psychology: General, 127, 55-68. doi: 10.1037/0096-3445.127.1.55

Beran, M. J., Smith, J. D., Coutinho, M. V. C., Couchman, J. J., \& Boomer, J. (2009). The psychological organization of "uncertainty" responses and "middle" responses: A dissociation in capuchin monkeys (Cebus apella). Journal of Experimental Psychology: Animal Behavior Processes, 35, 371-381. doi:10.1037/a0014626

Beran, M. J., Smith, J. D., \& Perdue, B. M. (2013). Language-trained chimpanzees (Pan troglodytes) name what they have seen but look first at what they have not seen. Psychological Science, 24, 660-666. doi: $10.1177 / 0956797612458936$

Besken, M., \& Mulligan, N. W. (2013). Easily perceived, easily remembered? Perceptual interference produces a double dissociation between metamemory and memory performance. Memory \& Cognition. doi: 10.3758/s13421-013-0307-8

Bjork, R. A., Dunlosky, J., \& Kornell, N. (2012). Self-regulated learning: Beliefs, techniques, and illusions. Annual Review of Psychology, 64, 417-444. doi:10.1146/annurev-psych-113011-143823

Bolles, R., \& Petrinovich, L. (1954). A technique for obtaining rapid drive discrimination in the rat. Journal of Comparative and Physiological Psychology, 47, 378-380. doi:10.1037/h0060058

Call, J. (2010). Do apes know that they could be wrong? Animal Cognition, 13, 689-700. doi:10.1007/s10071-010-0317-x

Call, J., \& Carpenter, M. (2001). Do apes and children know what they have seen? Animal Cognition, 3, 207-220. doi:10.1007/s100710100078

Couchman, J. J., Coutinho, M. V. C., Beran, M. J., \& Smith, J. D. (2010). Beyond stimulus cues and reinforcement signals: A new approach to animal metacognition. Journal of Comparative Psychology, 124, $356-$ 368. doi:10.1037/a0020129

Crystal, J. D., \& Foote, A. L. (2011). Evaluating information-seeking approaches to metacognition. Current Zoology, 57, 531-542.

Dunlosky, J., \& Bjork, R. A. (Eds.). (2008). A handbook of metamemory and memory. Hillsdale, NJ: Psychology Press.

Dunlosky, J., \& Nelson, T. O. (1992). Importance of the kind of cue for judgments of learning (JOL) and the delayed-JOL effect. Memory \& Cognition, 20, 374-380. doi:10.3758/BF03210921

Gallup, G. G. (1970). Chimpanzees: Self-recognition. Science, 167(3914), 86-87. doi:10.1126/science.167.3914.86

Hampton, R. R. (2001). Rhesus monkeys know when they remember. Proceedings of the National Academy of Sciences, USA, 98, 5359-5362. doi:10.1073/pnas.071600998 
Hampton, R. R. (2009). Multiple demonstrations of metacognition in nonhumans: Converging evidence or multiple mechanisms? Comparative cognition \& behavior reviews, 4, 17-28.

Hampton, R. R., Zivin, A., \& Murray, E. A. (2004). Rhesus monkeys (Macaca mulatta) discriminate between knowing and not knowing and collect information as needed before acting. Animal Cognition, 7, 239246. doi:10.1007/s10071-004-0215-1

Hart, J. T. (1967). Memory and the memory-monitoring process. Journal of Verbal Learning and Verbal Behavior, 6, 685-691. doi:10.1016/ S0022-5371(67)80072-0

Inman, A., \& Shettleworth, S. J. (1999). Detecting metamemory in nonverbal subjects: A test with pigeons. Journal of Experimental Psychology: Animal Behavior Processes, 25, 389-395. doi:10.1037/0097-7403 .25 .3 .389

Jacoby, L., \& Kelley, C. M. (1987). Unconscious influences of memory for a prior event. Personality and Social Psychology Bulletin, 13, 314-336. doi: $10.1177 / 0146167287133003$

Jameson, K. A., Narens, L., Goldfarb, K., \& Nelson, T. O. (1990). The influence of near-threshold priming on metamemory and recall. Acta Psychologica, 73, 55-68. doi:10.1016/0001-6918(90)90058-N

Kelley, C. M., \& Jacoby, L. L. (1996). Adult egocentrism: Subjective experience versus analytic bases for judgment. Journal of Memory and Language, 35, 157-175. doi:10.1006/jmla.1996.0009

Kelley, C. M., \& Lindsay, D. S. (1993). Remembering mistaken for knowing: Ease of retrieval as a basis for confidence in answers to general knowledge questions. Journal of Memory and Language, 32, 1-24. doi:10.1006/jmla.1993.1001

Koriat, A. (1997). Monitoring one's own knowledge during study: A cue-utilization approach to judgments of learning. Journal of Experimental Psychology: General, 126, 349-370. doi:10.1037/0096-3445 .126 .4 .349

Kornell, N. (2009). Metacognition in humans and animals. Current Directions in Psychological Science, 18, 11-15. doi:10.1111/j.1467-8721 2009.01597.x

Kornell, N., Rhodes, M. G., Castel, A. D., \& Tauber, S. K. (2011). The ease of processing heuristic and the stability bias: Dissociating memory, memory beliefs, and memory judgments. Psychological Science, 22, 787-794. doi:10.1177/0956797611407929

Kornell, N., Son, L. K., \& Terrace, H. S. (2007). Transfer of metacognitive skills and hint seeking in monkeys. Psychological Science, 18, 64-71. doi:10.1111/j.1467-9280.2007.01850.x

Le Pelley, M. E. (2012). Metacognitive monkeys or associative animals? Simple reinforcement learning explains uncertainty in nonhuman animals. Journal of Experimental Psychology: Learning, Memory, and Cognition, 38, 686-708. doi:10.1037/a0026478

Magnussen, S., Andersson, J., Cornoldi, C., De Beni, R., Endestad, T., Goodman, G. S., . . . Zimmer, H. (2006). What people believe about memory. Memory, 14, 595-613. doi:10.1080/09658210600646716

Matvey, G., Dunlosky, J., \& Guttentag, R. (2001). Fluency of retrieval at study affects judgments of learning (JOLs): an analytic or nonanalytic basis for JOLs? Memory \& Cognition, 29, 222-233. doi:10.3758/ BF03194916

Metcalfe, J., \& Kober, H. (2005). Self-reflective consciousness and the projectable self. In H. S. Terrace \& J. Metcalfe (Eds.), The missing link in cognition: Origins of self-reflective consciousness. New York, NY: Oxford University Press. doi:10.1093/acprof:oso/9780195161564.003 .0002

Metcalfe, J., Schwartz, B. L., \& Joaquim, S. G. (1993). The cue familiarity heuristic in metacognition. Journal of Experimental Psychology: Learning, Memory, and Cognition, 19, 851-861.

Metcalfe, J. (2003). Drawing the line on metacognition. Behavioral and Brain Sciences, 26, 350-351. doi:10.1017/S0140525X03340087

Nelson, T. O., Dunlosky, J., Graf, A., \& Narens, L. (1994). Utilization of metacognitive judgments in the allocation of study during multitrial learning. Psychological Science, 5, 207-213. doi:10.1111/j.1467-9280 1994.tb00502.x

Nestle, M. (2011). Ketchup is a vegetable? Again? The Atlantic. Retrieved October 26, 2012, from http://www.theatlantic.com/health/archive/2011/ 11/ketchup-is-a-vegetable-again/248538/

Reder, L. M., \& Ritter, F. E. (1992). What determines initial feeling of knowing? Familiarity with question terms, not with the answer. Journal of Experimental Psychology: Learning, Memory, and Cognition, 18, 435-451. doi:10.1037/0278-7393.18.3.435

Reder, L. M. (1987). Strategy selection in question answering. Cognitive Psychology, 19, 90-138. doi:10.1016/0010-0285(87)90005-3

Reder, L. M., \& Schunn, C. (1996). Metacognition does not imply awareness: Strategy choice is governed by implicit learning and memory. In L. M. Reder (Ed.), Implicit memory and metacognition (pp. 45-77). Mahwah, NJ: Erlbaum

Redford, J. S. (2010). Evidence of metacognitive control by humans and monkeys in a perceptual categorization task. Journal of Experimental Psychology: Learning, Memory, and Cognition, 36, 248-254. doi: 10.1037/a0017809

Rhodes, M. G., \& Castel, A. D. (2008). Memory predictions are influenced by perceptual information: Evidence for metacognitive illusions. Journal of Experimental Psychology: General, 137, 615-625. doi:10.1037/ a0013684

Rhodes, M. G., \& Castel, A. D. (2009). Metacognitive illusions for auditory information: Effects on monitoring and control. Psychonomic Bulletin \& Review, 16, 550-554. doi:10.3758/PBR.16.3.550

Schwartz, B. L. (2002). Tip-of-the-tongue states: Phenomenology, mechanism, and lexical retrieval. Mahwah, NJ: Erlbaum.

Schwartz, B. L., Benjamin, A. S., \& Bjork, R. A. (1997). The inferential and experiential basis of metamemory. Current Directions in Psychological Science, 6, 132-137. doi:10.1111/1467-8721.ep10772899

Schwartz, B. L., \& Metcalfe, J. (1992). Cue familiarity but not target retrievability enhances feeling-of-knowing judgments. Journal of Experimental Psychology: Learning, Memory, and Cognition, 18, 1074-1083.

Shields, W. E., Smith, J. D., \& Washburn, D. A. (1997). Uncertain responses by humans and rhesus monkeys (Macaca mulatta) in a psychophysical same-different task. Journal of Experimental Psychology: General, 126, 147-164. doi:10.1037/0096-3445.126.2.147

Smith, J. D. (2009). The study of animal metacognition. Trends in Cognitive Sciences, 13, 389-396. doi:10.1016/j.tics.2009.06.009

Smith, J. D., Beran, M. J., Couchman, J. J., \& Coutinho, M. V. C. (2008). The comparative study of metacognition: Sharper paradigms, safer inferences. Psychonomic Bulletin \& Review, 15, 679-691. doi:10.3758/ PBR.15.4.679

Smith, J. D., Beran, M. J., Couchman, J. J., Coutinho, M. V. C., \& Boomer, J. B. (2009). Animal metacognition: Problems and prospects. Comparative Cognition \& Behavior Reviews, 4, 40-53. doi:10.3819/ccbr.2009 .40004

Smith, J. D., Beran, M. J., Redford, J. S., \& Washburn, D. A. (2006). Dissociating uncertainty responses and reinforcement signals in the comparative study of uncertainty monitoring. Journal of Experimental Psychology: General, 135, 282-297. doi:10.1037/0096-3445.135.2.282

Smith, J. D., Schull, J., Strote, J., McGee, K., Egnor, R., \& Erb, L. (1995). The uncertain response in the bottlenosed dolphin (Tursiops truncates). Journal of Experimental Psychology: General, 124, 391-408. doi:10.1037/0096-3445.124.4.391

Smith, J. D., Shields, W. E., Allendoerfer, K. R., \& Washburn, D. A. (1998). Memory monitoring by animals and humans. Journal of Experimental Psychology: General, 127, 227-250. doi:10.1037/0096-3445 127.3.227

Smith, J. D., Shields, W. E., \& Washburn, D. A. (2003). The comparative psychology of uncertainty monitoring and metacognition. Behavioral and Brain Sciences, 26, 317-339. doi:10.1017/S0140525X03000086

Son, L. K., \& Kornell, N. (2005). Metaconfidence judgments in rhesus 
macaques: Explicit versus implicit mechanisms. In H. S. Terrace \& J. Metcalfe (Eds.), The Missing link in cognition: Origins of self-reflective consciousness (pp. 296-320). Oxford, UK: Oxford University Press. doi:10.1093/acprof:oso/9780195161564.003.0012

Son, L. K., \& Kornell, N. (2008). Research on the allocation of study time: Key studies from 1890 to the present (and beyond). In J. Dunlosky \& R. A. Bjork (Eds.), A handbook of memory and metamemory (pp. 333-351). Hillsdale, NJ: Psychology Press.

Sutton, J. E., \& Shettleworth, S. J. (2008). Memory without awareness: Pigeons do not show metamemory in delayed matching to sample. Journal of Experimental Psychology: Animal Behavior Processes, 34, 266-282. doi:10.1037/0097-7403.34.2.266

Templer, V. L., \& Hampton, R. R. (2012). Rhesus monkeys (Macaca mulatta) show robust evidence for memory awareness across multiple generalization tests. Animal Cognition, 15, 409-419. doi:10.1007/ s10071-011-0468-4
Terrace, H. S., \& Metcalfe, J. (Eds.). (2005). The missing link in cognition. Origins of self-reflective consciousness. Oxford, UK: Oxford University Press. doi:10.1093/acprof:oso/9780195161564.001.0001

Terrace, H. S., \& Son, L. K. (2009). Comparative metacognition. Current Opinion in Neurobiology, 19, 67-74. doi:10.1016/j.conb.2009.06.004

Undorf, M., \& Erdfelder, E. (2011). Judgments of learning reflect encoding fluency: Conclusive evidence for the ease-of-processing hypothesis Journal of Experimental Psychology: Learning, Memory, and Cognition, 37, 1264-1269. doi:10.1037/a0023719

Received November 1, 2012

Revision received May 16, 2013

Accepted May 20, 2013

\section{Members of Underrepresented Groups: Reviewers for Journal Manuscripts Wanted}

If you are interested in reviewing manuscripts for APA journals, the APA Publications and Communications Board would like to invite your participation. Manuscript reviewers are vital to the publications process. As a reviewer, you would gain valuable experience in publishing. The P\&C Board is particularly interested in encouraging members of underrepresented groups to participate more in this process.

If you are interested in reviewing manuscripts, please write APA Journals at Reviewers@apa.org. Please note the following important points:

- To be selected as a reviewer, you must have published articles in peer-reviewed journals. The experience of publishing provides a reviewer with the basis for preparing a thorough, objective review.

- To be selected, it is critical to be a regular reader of the five to six empirical journals that are most central to the area or journal for which you would like to review. Current knowledge of recently published research provides a reviewer with the knowledge base to evaluate a new submission within the context of existing research.

- To select the appropriate reviewers for each manuscript, the editor needs detailed information. Please include with your letter your vita. In the letter, please identify which APA journal(s) you are interested in, and describe your area of expertise. Be as specific as possible. For example, "social psychology" is not sufficient-you would need to specify "social cognition" or "attitude change" as well.

- Reviewing a manuscript takes time (1-4 hours per manuscript reviewed). If you are selected to review a manuscript, be prepared to invest the necessary time to evaluate the manuscript thoroughly.

APA now has an online video course that provides guidance in reviewing manuscripts. To learn more about the course and to access the video, visit http://www.apa.org/pubs/authors/reviewmanuscript-ce-video.aspx. 